УДК 630*266:633.873.1(470.44)

ЗАКОНОМЕРНОСТИ СОСТОЯНИЯ, РОСТА И ПРОДУКТИВНОСТИ ДРЕВЕСНЫХ ПОРОД В ЛЕСНЫХ ПОЛОСАХ ОРОШАЕМОЙ СТЕПИ САРАТОВСКОГО ЗАВОЛЖЬЯ

\author{
Маштаков Д.А., Садыков А.P.
}

ФГБОУ ВО Саратовский государственный аграрный университет имени Н.И. Вавилова, Саратов, e-mail: lmsus1920@mail.ru

\begin{abstract}
Целью исследований явилось установление закономерностей роста и продуктивности древесных пород в лесных полосах орошаемой степи Саратовского Заволжья на основе исследований 2017-2019 гг. Объект исследования расположен в степи Саратовского Заволжья на территории ЗАО «Племенной завод «Мелиоратор»»» Марксовского района Саратовской области. Полевые исследования и обработка материалов проводились в соответствии с методическими указаниями профильных НИИ России (ВНИАЛМИ). Исследуемые лесные полосы имеют древесно-теневой тип смешения с главными породами дубом черешчатым и вязом приземистым и сопутствующей породой - ясенем ланцетным. Лесные полосы, являясь экологическим каркасом агроландшафта, защищают сельскохозяйственные угодья от действия неблагоприятных природных факторов, повышая продуктивность сельскохозяйственных культур и обеспечивая оптимальное использование режима орошения. Важнейшими показателями долговечности, биологической продуктивности и, как следствие, эффективности лесомелиоративного воздействия на прилегающую территорию являются состояние и рост древесных пород в лесных полосах. Исследования показали, что таксационные показатели дуба черешчатого при его смешении с ясенем выше на $20 \%$, чем при смешении дуба с вязом приземистым. Рост дуба по высоте и диаметру при смешении с ясенем начиная с 6-летнего возраста и на протяжении всей жизни превышает аналогичные показатели дуба при его смешении с вязом на 20\%. Таксационные показатели вяза приземистого и его рост при его смешении с дубом и ясенем превышают аналогичные показатели вяза в чистых насаждениях на 9-11,5\%. Исследование жизненного состояния дуба в лесных полосах показало, что при смешении дуба с ясенем преобладали «слабоугнетенные» деревья (46\%) и «здоровые» деревья (45\%) дуба, а при смешении дуба с вязом приземистым количество «здоровых» деревьев дуба сократилось на $6 \%$, «слабоугнетенных» и «сильноугнетенных» возросло на 3,6\% и 5,3\% соответственно.
\end{abstract}

Ключевые слова: лесная полоса, орошаемые почвы, таксационная характеристика, жизненное состояние, ход роста, главная порода, сопутствующая порода

\title{
PATTERNS IN CONDITION, GROWTH AND PRODUCTIVITY OF TREE SPECIES IN FOREST BELTS OF IRRIGATED STEPPE OF SARATOV TRANS-VOLGA REGION
}

\begin{abstract}
Mashtakov D.A., Sadykov A.R.
Federal State Budgetary Educational Institution of Higher Education «Saratov State Vavilov Agrarian University named after N.I.Vavilov», Saratov, e-mail: Imsus1920@mail.ru

The purpose of the research was to establish regularities of growth and productivity of tree species in forest strips of the irrigated steppe of Saratov Volga region based on 2017-2019 research. The object of research is located in the steppe of the Saratov Volga region on the territory of JSC «Breeding plant» Meliorator» of Marksovsky district of Saratov region. Field research and processing of materials was carried out in accordance with the guidelines of specialized research institutes of Russia (VNIALMI). The studied forest strips have a tree-shadow type of mixing with the main species of oak and elm squat and accompanying species-lanceolate ash. Forest belts, being the ecological framework of the agricultural landscape, protect agricultural land from the effects of adverse natural factors, increasing productivity of crops and ensuring optimal use of irrigation regime. The most important indicator of longevity, biological productivity and, as a result, the effectiveness of forest reclamation impact on the surrounding area is the state and growth of tree species in forest strips. Research has shown that taxational indicators of the cherry oak when it is mixed with ash are $20 \%$ higher than when it is mixed with the squat elm. The growth of oak in height and diameter when mixed with ash, starting from 6 years of age and throughout life exceeds the similar indicators of oak when mixed with elm by $20 \%$. Taxational indicators of squat elm and its growth when mixed with oak and ash exceed similar indicators of elm in clean stands by $9-11.5 \%$. A study of life status of oak in woodlands showed us that when oak and ash were mixed, «low-carbon» trees $(46 \%)$ and «healthy» trees $(45 \%)$ of oak prevailed, and when oak and elm were mixed, the number of «healthy» oak trees decreased by $6 \%$, «lowcarbon» and «high-carbon» trees increased by $3.6 \%$ and $5.3 \%$, respectively.
\end{abstract}

Keywords: forest belt, irrigated soils, taxonomic characteristics, vital status, the course of growth, the main species, the related species

Защитные лесные насаждения на территории орошаемых агроландшафтов обеспечивают защиту сельскохозяйственных угодий от действия неблагоприятных природных факторов. Изменяя микроклимат прилегающих к лесным полосам сельхозугодий, они повышают их продуктивность, снижают расход поливной воды и обеспечивают выполнение режима орошения сельскохозяйственных культур. Важнейшими показателями долговечности, биологической продуктивности и, как следствие, максимальной продолжительности мелиоративного эффекта лесных полос являются 
состояние и рост древесных пород [1-3]. Исследованием особенностей роста, биопродуктивности древесных пород в защитных лесных насаждениях занимались В.И. Михин, Е.А. Михина, В.В. Танюкевич, В.М. Ивонин, Н.Н. Дубенок и другие ученые [4-6]. В условиях Саратовского Заволжья главными породами в лесных полосах являются дуб черешчатый (Quercus robur L.) и вяз приземистый (Ulmus pumila L.), рост и состояние которых во многом зависят от применяемого взаимного смешения этих пород между собой и с сопутствующей породой - ясенем ланцетным (Fracsinus lanceolata L.) [2, 7].

Цель исследований: выявление закономерностей состояния, роста и продуктивности древесных пород в защитных лесных насаждениях орошаемой степи Саратовского Заволжья.

\section{Материалы и методы исследований}

Объект исследования - система защитных лесных насаждений на орошаемых черноземах ЗАО «Племенной завод «Мелиоратор»»» Марксовского района Саратовской области. На опытном участке размещаются 4 лесные полосы 6- и 5-рядные с разными схемами смешения и видовым составом древесных пород. Все полосы имели схему посадки 3х0,8 м, возраст - 39 лет, конструкцию плотную, лесная полоса с дубом черешчатым и ясенем ланцетным имела ажурную конструкцию.

Полоса № 1. 6-рядная, схема смещения Вп-Д-Д-Д-Д-Вп. Ширина полосы - 18 м. Густота посадки на 1 га: дуба - 2750 шт., вяза - 1375 шт. Сохранность дуба - 48\%, вяза - 56\%. Полоса № 2. 6-рядная. Схема смешения Вп-Вп-Вп-Вп-Вп-Вп. Ширина полосы - 18 м. Густота посадки на 1 га -4125 шт. Сохранность 46\%. Полоса № 3 - 5-рядная. Схема смешения ЯлД-Д-Д-Ял. Ширина полосы - 15 м. Сохранность дуба - 52\%, ясеня - 47\%. Полоса № 4 - 6-рядная. Схема смешения Ял-ВпВп-Вп-Вп-Ял. Ширина полосы - 18 м. Сохранность вяза - 50\%, ясеня $-47 \%$. Техника орошения - дождевальная машина «Фрегат» кругового действия с забором воды из закрытого трубопровода и подачей воды из оросительного канала. Режим орошения - принятый в данном хозяйстве. Почвы опытного участка - темно-каштановые, средне- и тяжелосуглинистые.

Исследования роста, таксационных показателей и продуктивности древесных пород проводились согласно методике
ВНИАЛМИ [8]. Закладка пробных площадей и их исследование осуществлялись согласно ОСТ 56-69-83 [9]. Определение жизненного состояния древесных пород в лесных полосах проводилось по методике В.А. Алексеева [10].

\section{Результаты исследования и их обсуждение}

В Саратовском Заволжье лесные полосы выполняют различные функции, главная из которых - защита сельскохозяйственных угодий от действия неблагоприятных природных факторов. Древесные породы в лесных полосах обладают разными таксационными показателями, ростом, продуктивностью, состоянием, которые зависят не только от почвенных и климатических условий произрастания, но и от применяемых схем смешения. Исследуемые лесные полосы представлены главными породами дубом черешчатым (Quercus robur L.) и вязом приземистым (Ulmus pumila L.). В качестве сопутствующей породы выступает ясень зеленый (Fracsinus lanceolata L.). Таксационная характеристика исследуемых лесных полос представлена в табл. 1. В лесной полосе с дубом и вязом вяз занимает крайние ряды и имеет высоту на 29,7\%, а диаметр - на 22,6\% превышающие аналогичные показатели дуба (табл. 1). Дуб, занимающий центральные ряды, имеет высоту 14,8 м и диаметр 21,2 см, что соответственно на $12,1 \%$ и 7,5\% меньше аналогичных показателей дуба в лесополосе с ясенем ланцетным (табл. 1). В смешении с ясенем дуб растет по II классу бонитета, тогда как в смешении с вязом - по III классу бонитета. Вяз как быстрорастущая породы обгоняет дуб по высоте, развивая мощную крону, которая притеняет и охлестывает крону дуба центральных рядов полосы, тем самым оказывая негативное влияние на рост дуба. В чистой вязовой лесополосе высота вяза на $17 \%$, а диаметр на $18,2 \%$ меньше аналогичных показателей вяза в смешении с дубом (табл. 1). Вяз, занимающий центральные ряды, находится в более стесненных условиях и имеет меньшую влагообеспеченность по сравнению с вязом в крайних рядах лесополосы с дубом черешчатым, что отражается на его таксационных показателях (табл. 1).

В лесной полосе с вязом и ясенем вяз растет по II классу бонитета и имеет высоту на $11,5 \%$ большую высоты вяза в чисто вязовой лесополосе (табл. 1). 
Таксационная характеристика лесных полос на орошаемых

Таблица 1 темно-каштановых почвах степного Заволжья

\begin{tabular}{|c|c|c|c|c|c|c|c|c|c|}
\hline \multirow{2}{*}{$\begin{array}{l}\text { № } \\
\Pi / \Pi\end{array}$} & \multirow{2}{*}{$\begin{array}{l}\text { Схема смешения } \\
\text { Число рядов }\end{array}$} & \multirow{2}{*}{$\begin{array}{c}\text { Размещение, м } \\
\text { Ширина, м }\end{array}$} & \multirow{2}{*}{$\begin{array}{c}\text { Поро- } \\
\text { да }\end{array}$} & \multirow{2}{*}{\begin{tabular}{|c} 
Густота, \\
шт/га
\end{tabular}} & \multirow{2}{*}{$\begin{array}{l}\text { Сохран- } \\
\text { ность, } \%\end{array}$} & \multirow{2}{*}{$\begin{array}{c}\text { Bозраст, } \\
\text { лет }\end{array}$} & \multicolumn{2}{|c|}{ Средние } & \multirow{2}{*}{$\begin{array}{l}\text { Бони- } \\
\text { тет }\end{array}$} \\
\hline & & & & & & & $\mathrm{H}, \mathrm{M}$ & Д, см & \\
\hline \multirow[t]{2}{*}{1} & \multirow{2}{*}{$\frac{\text { Вп-Д-Д-Д-Д-ВП }}{6}$} & \multirow{2}{*}{$\frac{3 \times 0,8}{18}$} & Д & 2750 & 48 & 39 & 14,8 & 21,2 & III \\
\hline & & & Вп & 1375 & 56 & 39 & 19,2 & 26,0 & I \\
\hline \multirow[t]{2}{*}{2} & \multirow{2}{*}{$\begin{array}{c}\text { Вп-Вп-Вп-Вп-Вп-Вп } \\
6\end{array}$} & \multirow{2}{*}{$\frac{3 \times 0,8}{18}$} & & & & & & & \\
\hline & & & Вп & 4125 & 46 & 39 & 16,4 & 22,0 & II \\
\hline \multirow[t]{2}{*}{3} & \multirow{2}{*}{ 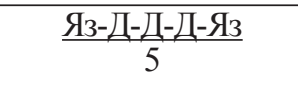 } & \multirow{2}{*}{$\frac{3 \times 0,8}{15}$} & Д & 2475 & 52 & 39 & 16,6 & 22,8 & II \\
\hline & & & Яз & 1650 & 47 & 39 & 13,5 & 18,0 & III \\
\hline \multirow[t]{2}{*}{4} & \multirow{2}{*}{$\frac{\text {, }_{3}-В \Pi-В \Pi-В п-В п-Я_{3}}{6}$} & \multirow{2}{*}{$\frac{3 \times 0,8}{18}$} & Вп & 2750 & 50 & 39 & 18,3 & 23,1 & II \\
\hline & & & Яз & 1375 & 45 & 39 & 14,7 & 19,0 & III \\
\hline
\end{tabular}

П р и м е ч а н и е : ВП - вяз приземистый; Д - дуб черешчатый; Яз - ясень зеленый.

Таблица 2

Рост древесных пород в разных рядах лесной полосы

\begin{tabular}{|c|c|c|c|c|c|c|c|c|}
\hline \multirow{2}{*}{$\begin{array}{c}\text { № } \\
\Pi / \Pi\end{array}$} & \multirow[t]{2}{*}{ Порода } & \multirow{2}{*}{$\begin{array}{c}\text { Возраст, } \\
\text { лет }\end{array}$} & \multicolumn{2}{|c|}{ Опушечный ряд } & \multicolumn{2}{|c|}{ Центральный ряд } & \multicolumn{2}{|c|}{ Различие, \% } \\
\hline & & & Высота, м & Диаметр, см & Высота, м & Диаметр, см & По высоте & По диаметру \\
\hline 1 & $\begin{array}{c}\text { ВП } \\
\text { Д }\end{array}$ & $\begin{array}{l}39 \\
39\end{array}$ & $\begin{array}{c}19,2 \\
-\end{array}$ & $\begin{array}{c}26,0 \\
-\end{array}$ & $\overline{14,8}$ & $-\overline{21,2}$ & 29,7 & 22,6 \\
\hline 2 & Вп & 39 & 17,9 & 25,3 & 15,0 & 20,2 & 19,3 & 25,2 \\
\hline 3 & $\begin{array}{l}\text { Я3 }_{3} \\
\text { Д }\end{array}$ & $\begin{array}{l}39 \\
39 \\
\end{array}$ & $\begin{array}{c}13,5 \\
- \\
\end{array}$ & $\begin{array}{c}18,0 \\
- \\
\end{array}$ & $-\overline{16,6}$ & $2 \overline{22,8}$ & 22,9 & 26,7 \\
\hline 4 & $\begin{array}{l}Я_{3} \\
\mathrm{~B}_{1} \\
\end{array}$ & $\begin{array}{l}39 \\
39 \\
\end{array}$ & $\begin{array}{c}14,7 \\
- \\
\end{array}$ & $\begin{array}{c}19,0 \\
- \\
\end{array}$ & $\overline{18,3}$ & 23,1 & 24,5 & 21,5 \\
\hline
\end{tabular}

П р и м е ч а н и е : ВП - вяз приземистый; Д - дуб черешчатый; Яз - ясень зеленый.

Разница в высоте древесных пород крайних и центральных рядов оказывает существенное влияние на форму поперечного профиля лесополосы, который в свою очередь определяет ее мелиоративный эффект и долговечность. Разница высоты крайних рядов вяза приземистого и центральных рядов дуба черешчатого составляет $29,7 \%$, лесополоса имеет вогнутый поперечный профиль, оказывающий негативное влияние на аэродинамические характеристики лесной полосы, на ее устойчивость и долговечность. В вязовой лесной полосе разница в таксационных показателях вяза крайних и центральных рядов составляет по высоте $19,3 \%$, по диаметру $25,2 \%$ (табл. 2). Полоса имеет вогнутый поперечный профиль, негативно влияющий на мелиоративную эффективность, устойчивость и долговечность лесополосы.

Разница в таксационных показателях дуба, занимающего центральные ряды, и ясеня, занимающего крайние ряды, составляет: по высоте - 23,0\%, по диаметру -
$26,7 \%$ в пользу дуба (табл. 2). Полоса имеет выпуклый поперечный профиль, который является более эффективным по мелиоративному эффекту, долговечности и устойчивости полосы. Таким же выпуклым поперечным профилем обладает лесополоса с вязом приземистым и ясенем ланцетным (табл. 2), где разница по высоте между крайними рядами ясеня и центральными рядами вяза составляет $24,5 \%$.

Анализ роста дуба черешчатого по высоте в смешении с ясенем и вязом показал, что примерно до 5-летнего возраста высота дуба была идентична при смешении с обеими породами (рис. 1).

С 5-летнего возраста и до возраста 39 лет наблюдается превышение интенсивности роста дуба в смешении с ясенем на 10-20\% (рис. 1). Среднегодовой прирост дуба по высоте в смешении с ясенем составил 0,32-0,47 м/год, тогда как прирост дуба по высоте в смешении с вязом 0,24-0,38 м/год, причем наибольший прирост дуба отмечался с 15 до 25 лет 
со снижением к 39 годам. Рост вяза приземистого в высоту был наиболее интенсивен при смешении вяза с дубом, где разница в росте по сравнению с чисто вязовой лесополосой и смешением с ясенем наблюдалась примерно с 3-летнего возраста вяза и составила 4-13\% по сравнению с ростом вяза в смешении с ясенем и 15$19 \%$ по сравнению с ростом вяза в чистой вязовой лесополосе (рис. 2). Среднегодовой прирост вяза по высоте в смешении с дубом составил 0,48-0,67 м/год, в смешении с ясенем - 0,46-0,66 м/год и в чистой вязовой лесополосе - 0,42-0,61 м/год (рис. 2). Наибольшие приросты вяза отмечались с 5 до 20 лет при его смешении с дубом и ясенем с дальнейшим постепенным снижением к 39-летнему возрасту. В чистой вязовой лесополосе пик среднегодового прироста по высоте произошел к 10-летнему возрасту с постепенным его снижением на протяжении всего возраста полосы (рис. 2).

В исследуемых лесополосах отмечаются различия в состоянии дуба и вяза при разном смешении (табл. 3).

В лесных полосах с дубом преобладают деревья 2-го класса жизненного состояния - «слабоугнетенные», которых отмечалось 46 \% при смешении дуба с ясенем и 49,6\% при смешении дуба с вязом (табл. 3). Деревья 1-го класса жизненного состояния - «здоровые» - составили $45 \%$ при смешении дуба с ясенем и $35 \%$ при смешении дуба с вязом (табл. 3). В лесных полосах с вязом при смешении со всеми породами преобладает 2-й класс жизненного состояния (табл. 3). «Здоровые» деревья вяза (41\%) преобладали при смешении вяза с дубом.

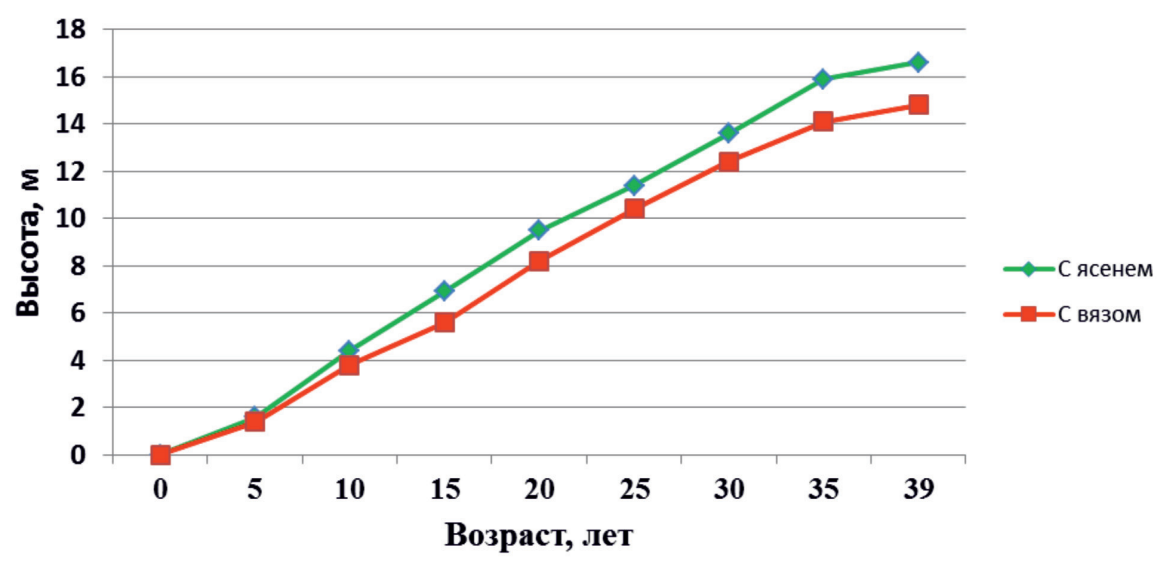

Рис. 1. Ход роста дуба черешчатого по высоте при разном смешении

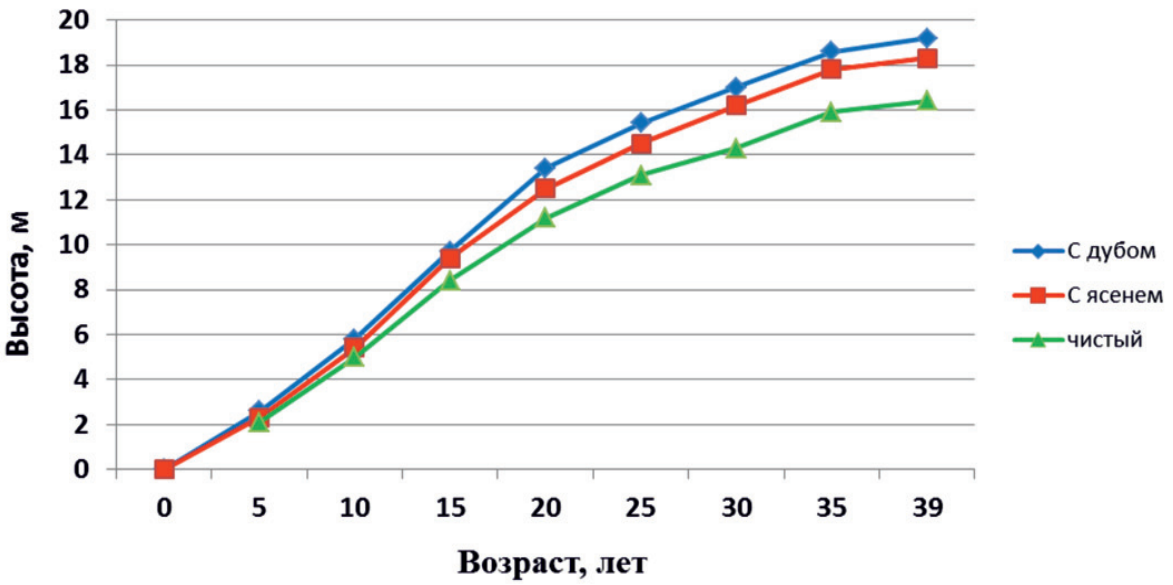

Рис. 2. Ход роста вяза приземистого по высоте при разном смешении 
Жизненное состояние древесных пород в лесных полосах

Таблица 3

\begin{tabular}{|c|c|c|c|c|c|c|}
\hline \multirow{2}{*}{$\begin{array}{c}\text { № } \\
\text { П/П }\end{array}$} & Порода & \multicolumn{5}{|c|}{ Число деревьев по классам жизненного состояния, \% } \\
\cline { 3 - 7 } & & 1 & 2 & 3 & 4 & 5 \\
\hline 1 & Вп & 41,0 & 43,5 & 9,5 & 4,2 & 1,8 \\
& Д & 35,0 & 49,6 & 11,8 & 2,2 & 1,4 \\
\hline 2 & Вп & 30,0 & 45,5 & 15,8 & 6,2 & 2,5 \\
\hline 3 & Яз & 34,5 & 49,8 & 10,7 & 3,2 & 1,8 \\
& Д & 45,0 & 46,0 & 6,5 & 1,5 & 1,0 \\
\hline 4 & Яз & 41,0 & 48,3 & 7,6 & 1,8 & 1,3 \\
& Вп & 38,0 & 44,5 & 10,5 & 5,0 & 2,0 \\
\hline
\end{tabular}

П р и м е ч а н и е : ВП - вяз приземистый; Д - дуб черешчатый; Яз - ясень зеленый.

Смешение дуба с ясенем в условиях орошаемой степи Саратовского Заволжья обеспечило почти идентичное количество «здоровых» и «слабоугнетенных» деревьев дуба $-45 \%$ и $46 \%$ соответственно, которое позволяет сохранить оптимальную устойчивость, долговечность, продуктивность и мелиоративный эффект лесной полосы на должном уровне долгое время. Смешение вяза приземистого с ясенем, дубом и его состояние в чистой вязовой лесной полосе показали его лучшее состояние при смешении с ясенем, где количество «здоровых» деревьев было 38\%, а «слабоугнетенных» $44,5 \%$. В смешении с дубом вяз является сопутствующей породой из-за низкой долговечности и сильным конкурентом дуба.

\section{Заключение}

Дуб черешчатый в смешении с вязом растет по III классу бонитета, имеет высоту 14,8 м и диаметр 21,2 см, что на $12,1 \%$ и 7,5\% ниже соответствующих показателей дуба, растущего по II классу бонитета в смешении с ясенем. Вяз приземистый в смешении с дубом растет по I классу бонитета, имеет высоту 19,2 м и диаметр 26,0 cм, что на $17 \%$ и 18,2\% больше соответствующих показателей вяза, растущего по III классу бонитета в чистой вязовой лесополосе, и на 4,9\% и 12,5\% больше соответствующих показателей вяза, растущего по II классу бонитета в смешении с ясенем ланцетным. Во всех лесных полосах у дуба и вяза приземистого преобладают деревья 2-го класса жизненного состояния «слабоугнетенные», составляющие от 43,5\% для вяза при его смешении с дубом и до 49,5\% для дуба при его смешении с вязом. Смешение дуба черешчатого с вязом приземистым на орошаемых темно-каштановых почвах степи Саратовского Заволжья является неблагоприятным для роста дуба ввиду силь- ной конкуренции со стороны вяза. Лучшим спутником для дуба в условиях орошаемой степи Саратовского Заволжья является ясень ланцетный.

\section{Список литературы / References}

1. Михин В.И., Михина Е.А., Михина В.В. Формирование защитных лесных насаждений в Центральном Черноземье России // Успехи современного естествознания. 2018. № 12-1. C. 87-91.

Mikhin V. I., Mukhina E. A., Mikhina V. V. Formation of protective forest plantations in the Central black earth region of Russia // Advances in current natural sciences. 2018. № 12-1. P. 87-91 (in Russian).

2. Проездов П.Н., Карпушкин А.В., Дормидонтова Р.В., Рудько К.И. Биометрия древесных пород лесных полос в орошаемом сухостепном Заволжье // Основы рационального природопользования: сборник материалов V международной конференции (Саратов, 15-16 апреля 2016 г.). Саратов: СГАУ, 2016. С. 169-174.

Proezdov P.N., Karpushkin A.V., Dormidontova R.V., Rudko K.I. Biometrics of wood species of forest strips in the irrigated dry-steppe Zavolzhye// Osnovy ratsional'nogo prirodopol'zovaniya: sbornik materialov V mezhdunarodnoy konferentsii (Saratov, 15-16 aprelya 2016 g.). Saratov: SGAU, 2016. Р. 169-174 (in Russian).

3. Михин В.И., Михина Е.А., Михин Д.В. Особенности роста древесных пород в полезащитных насаждениях в условиях Среднерусской возвышенности // Актуальные направления научных исследований XXI века: теория и практика. 2015. Т. 3. № 5-2. С. 93-96. DOI: 10.12737/15978.

Mikhin V.I., Mukhina E.A., Mikhin D.V. Features of growth of wood species in protective plantings in the conditions of the Central Russian upland // Aktual'nyye napravleniya nauchnykh issledovaniy XXI veka: teoriya i praktika. 2015. V. 3. № 5-2. Р. 93-96 (in Russian).

4. Михин В.И., Михина Е.А. Формирование защитных насаждений из дуба черешчатого в Центральном Черноземье России // Лесотехнический журнал. 2018. Т. 8. № 4. C. 109-117. DOI: 10.12737/article_5c1a321965cf38.69751554.

Mikhin V.I., Mukhina E.A. Formation of protective plantings from a cherry oak in the Central Chernozem region of Russia // Lesotekhnicheskiy zhurnal. 2018. V. 8. № 4. P. 109117 (in Russian).

5. Танюкевич В.В., Ивонин В.М. Особенности хода роста основных пород лесных полос в Ростовской области // Вестник Московского государственного университета леса - Лесной вестник. 2012. № 2. C. 27-31.

Tanyukevich V.V., Ivonin V.M. Features of the growth of the main breeds of forest strips in the Rostov region // Vestnik Moskovskogo gosudarstvennogo universiteta lesa - Lesnoy vestnik. 2012. № 2. P. 27-31 (in Russian), 
6. Дубенок Н.Н., Танюкевич В.В., Тюрин С.В. Состояние и мелиоративная эффективность полезащитных лесонасаждений Краснодарского края // Российская сельскохозяйственная наука. 2017. № 1. С. 36-38.

Dubenok N.N., Tanyukevich V.V., Tyurin S.V. State and Reclamation Efficiency of Forest Shelterbelts of Krasnodar Krai. Russian agricultural science. 2017. V. 43. № 2. C. 170-172. DOI: $10.3103 / \mathrm{S} 1068367417020070$.

7. Маштаков Д.А., Садыков А.Р. Состояние защитных лесных насаждений в орошаемых условиях степи Саратовского Заволжья // Современное экологическое состояние природной среды и научно-практические аспекты рационального природопользования: сборник II международной научно-практической конференции (с. Соленое Займище, 2 февраля 2017 г.). Соленое Займище: ПНИИАЗ, 2017. C. $420-422$.

Mashtakov D.A., Sadykov A.R. State of protective forest plantations in the irrigated conditions of the steppe of the Saratov Zavolzhye // Sovremennoye ekologicheskoye sos- toyaniye prirodnoy sredy i nauchno-prakticheskiye aspekty ratsional'nogo prirodopol'zovaniya: sbornik II mezhdunarodnoy nauchno-prakticheskoy konferentsii (s. Solenoye Zaymishche, 2 fevralya 2017 g.). Solenoye Zaymishche: PNIIAZ, 2017. P. 420-422 (in Russian).

8. Баранов В.А., Бялый А.М., Павловский Е.С., Долгилевич М.И. Методика системных исследований лесоаграрных ландшафтов. М.: ВАСХНИЛ, ВНИАЛМИ, 1985. 112 с.

Baranov V.A., Bialyi A.M., Pavlovsky E.S., Dovgilevich M.I. The methodology of system research forest-agrarian landscapes. M.: VASKHNIL, VNIALMI, 1985. 112 p. (in Russian).

9. ОСТ 56-69-83 «Площади пробные лесоустроительные, метод закладки». М.: ЦБНТИлесхоз, 1984. 60 с.

10. Алексеев В.А. Диагностика жизненного состояния деревьев и древостоев // Лесоведение. 1989. № 4. С. 54-57.

Alekseev V.A. Diagnostics of the life state of trees and stands // Lesovedeniye. 1989. № 4. P. 54-57 (in Russian). 